\title{
Lack of genetic association of the three more common polymorphisms of CARD15 with psoriatic arthritis and psoriasis in a German cohort
}

\author{
J Lascorz, H Burkhardt, U Hüffmeier, B Böhm, F Schürmeyer-Horst, J Lohmann, \\ M Ständer, J Wendler, R Kelsch, C Baumann, W Küster, H Traupe, A Reis
}

\begin{abstract}
Objective: To determine whether the three common independent sequence variants of the putative pleiotropic nonMHC autoimmune gene CARD15 influence disease susceptibility in large German cohorts of patients with psoriatic arthritis and psoriasis vulgaris, before and after stratification to HLA-C.

Methods: DNA was obtained from 375 patients with psoriatic arthritis, 281 patients with psoriasis vulgaris without joint involvement, and 376 controls. The three variants of the CARD15 gene (R702W, G908R, leu1007fsinsC), and two single nucleotide polymorphisms of the HCR gene (HCR-325, HCR-2327) for HLA-C stratification were genotyped using allelic discrimination Taqman assays.

Results: No significant differences in genotype frequencies were observed between controls and either the psoriatic arthritis or the psoriasis vulgaris patient population, even after stratification to HLA-C in both patient cohorts, or to the type of joint involvement within the psoriatic arthritis group. Conclusions: The lack of genetic association between the most common Crohn's disease alleles of the CARD15 gene and psoriatic joint disease on large cohorts of white patients does not support a recently claimed role for CARD15 as the first non-MHC susceptibility gene in the pathogenesis of psoriatic arthritis, but confirms and extends previous studies in the case of psoriasis vulgaris.
\end{abstract}

$\mathrm{P}$ soriasis is an HLA associated, chronic inflammatory and hyperproliferative skin disorder that affects about $2 \%$ of the white population. Psoriatic arthritis is a heterogeneous inflammatory joint disease that affects approximately $5-15 \%$ of patients with psoriasis. CARD15 previously named NOD2, mapping to chromosome 16q12, has convincingly been shown to confer susceptibility to Crohn's disease ${ }^{12}$ owing to the insertion polymorphism leul007fsinsC. Patients with Crohn's disease have a sevenfold increased risk of developing psoriasis. ${ }^{3}$ Both diseases may lead to similar patterns of inflammatory involvement of the axial skeleton and peripheral joints. Moreover, bowel manifestations have also been demonstrated in a proportion of patients with psoriatic arthritis and are discussed as pathogenic factors in locomotor inflammation, although they usually present as subclinical forms and thus differ considerably in severity from Crohn's disease. ${ }^{4}$ Linkage studies have mapped a disease susceptibility locus in the chromosome 16 interval that contains the CARD15 gene for both psoriasis ${ }^{5}$ and psoriatic arthritis. ${ }^{6}$

Thus, CARD15 appeared to be an attractive candidate gene for psoriasis and psoriatic arthritis. In the case of psoriasis vulgaris, several studies have failed to find association either with the insertion leul007fsinsC, ${ }^{7}$ or with the other two common independent sequence variants of CARD15 mutations, $\arg 702$ to trp (R702W) and gly908 to $\arg (\mathrm{G} 908 \mathrm{R}){ }^{8}$ In contrast, disease association for psoriatic arthritis was reported in a Canadian cohort of 187 patients, specially with the R702W mutation. ${ }^{9}$ As earlier studies on related arthritic conditions-for example, familial spondyloarthropathies ${ }^{10}$ or rheumatoid arthritis ${ }^{11}$ - had failed to show association, a specific role of CARD15 was postulated as the first non-MHC susceptibility gene in psoriatic arthritis. ${ }^{9}$

However, a recent Italian study on 193 patients could not confirm the reported genetic association between CARDI5 polymorphisms and psoriatic arthritis. ${ }^{12}$ Based on these contradictory results obtained in relatively small cohorts of patients, we decided to analyse the three mutations (R702W, G908R, and leul007fsinsC) in two substantially enlarged German cohorts: one comprising 375 patients with psoriatic arthritis diagnosed by a board certified rheumatologist, and the other consisting of 281 patients with psoriasis vulgaris without joint involvement.

In order to test whether CARD15 polymorphisms are associated with certain clinical subphenotypes of psoriatic arthritis, we carried out a separate analysis upon patient stratification for the type of joint involvement.

Owing to the known considerable heterogeneity and well documented genetic association of psoriasis and psoriatic arthritis to the MHC locus (PSORS1), we stratified for the risk allele at this locus and tested again for association to the three polymorphisms. For stratification to PSORS1, we used an indirect procedure similar to that described by Asumalahti et $\mathrm{al}^{13}$ : the PSORSI genotype is deduced from a risk haplotype (HCR*WWCC) consisting of certain SNP alleles within the HCR gene, which is in strong linkage disequilibrium with HLA-C.

\section{METHODS}

\section{Patients and controls}

The 281 patients with psoriasis vulgaris were of German (white) origin and recruited through dermatology clinics at two psoriasis rehabilitation hospitals. Mean (SD) age of onset was 21.3 (9.4) years. The majority of patients suffered from plaque type psoriasis vulgaris. We excluded all patients with signs of psoriatic arthritis up to the time of recruitment, when mean age was 48 (11.1) years; $61 \%$ of the patients were male.

The 375 patients with psoriatic arthritis were similarly of German descent and recruited through four different rheumatological centres in Germany: one acute clinic, two

Abbreviations: HCR, Hox control region; SNP, single nucleotide polymorphism 
Table 1 Sequences of primers and TaqMan MGB probes for each polymorphism assay

\begin{tabular}{|c|c|c|}
\hline Polymorphism & TaqMan MGB-probes $\left(5^{\prime}-3^{\prime}\right)$ & Primers $\left(5^{\prime}-3^{\prime}\right)$ \\
\hline \multirow{2}{*}{ R702W } & wt: CCCTGCTCcGGCGC & F: CTGGCTGAGTGCCAGACAT \\
\hline & mut: CCCTGCTC†GGCGC & R: GGATGGAGTGGAAGTGCTTG \\
\hline \multirow{2}{*}{ G908R } & wt: CTCTGITGCCCCAGAAT & F: CTGTTGACTCTITTGGCCTITICAG \\
\hline & mut: TCTGTTGCgCCAGAAT & R: GCCACCTCAAGCTTGGTGAT \\
\hline \multirow{2}{*}{ leu1007fsinsC } & wt:CTGCAGGCCCTTGA & F: CAGGTTGTCCAATAACTGCATCAC \\
\hline & mut: CTGCAGGcCCCTTG & R: CAGACTTCCAGGATGGTGTCATT \\
\hline \multirow{2}{*}{ HCR-325 } & wt: GGTCcGGCTCCT & F: CAGCAGGCTGAGGTGATCGT \\
\hline & mut: AGGTCtGGCTCCTG & R: CCTGGGCCTCTAGCCTCATC \\
\hline \multirow{2}{*}{ HCR-2327 } & wt: CTCCAGCTcCAATC & F: CCTGAGTGAAGCCATTTCCAA \\
\hline & mut: TGCTCCAGCTgCAA & R: CTCCAACTGTCAGCTTAGC \\
\hline
\end{tabular}

rehabilitation hospitals, and one private practice. The diagnosis of psoriatic arthritis was made by a board certified rheumatologist according to the criteria of Moll and Wright. ${ }^{14}$ Clinical examination of all joints was carried out to record the pattern of peripheral and axial joint disease, in addition to the presence of skin and nail disease. Psoriatic arthritis was classified according to the pattern of peripheral joint disease as oligoarticular (less than five joints ever involved) or polyarticular (more than five joints ever involved). Spinal involvement was defined as a history of inflammatory back pain or radiological evidence of sacroiliitis or spondylitis. Patients with erosions in at least one joint on plain radiographs of hands and feet, or any other joint investigated, were regarded as having erosive arthritis.

The mean (SD) age of onset for psoriasis vulgaris was 30.1 (13.0) years; $59.9 \%$ of the patients were male. For $78 \%$ of the patients, the diagnosis of psoriatic arthritis was made three years or more before recruitment. Peripheral joint involvement was detectable in the majority of cases (343, or $91.4 \%$ ); this was oligoarticular in 85 patients and polyarticular in 258 ( $22.6 \%$ and $68.8 \%$ of the entire cohort, respectively). Spinal involvement was observed in 72 patients, accounting for $19.2 \%$ of the psoriatic arthritis cohort. Sacroiliits or spondylitis, or both, in those patients was partly associated with concomitant peripheral joint disease.

The 376 controls had no psoriasis vulgaris and no history or signs of inflammatory joint disease at the time of recruitment, when their mean age was 32 (10) years. All were German (white) healthy blood donors; $58.7 \%$ of probands were male.

\section{Genotyping}

We genotyped the three polymorphisms of the CARD15 gene (R702W or rs2066844, G908R or rs2066845, and leu1007sinsC or rs2066847) and the two single nucleotide polymorphisms (SNPs) of the HCR gene in positions 325 and $2327,{ }^{13}$ using allelic discrimination Taqman assays on a 7900HT sequence detection system (Applied Biosystems, Foster City, California, USA), with 10 ng of genomic DNA as a template in a $5 \mu \mathrm{l}$ Taqman reaction.
Sequences of probes and primers are listed in table 1. The genotyping rate was $>97 \%$ for all polymorphisms. Taqman genotypes for all polymorphisms were verified by direct sequencing in a set of 24 randomly chosen probands.

\section{Statistical analysis}

To determine significant differences in allele frequencies between the patient and control groups, a $\chi^{2}$ statistic was used. All SNPs were tested for Hardy-Weinberg equilibrium. Haplotypes of the HCR gene were reconstructed with the program PHASE ${ }^{15}$ to allow stratification for PSORSI.

\section{Ethics approval}

The study protocols were approved by the ethics committees of the University Hospitals of Erlangen and Münster, respectively, and before inclusion all individuals gave their informed consent. The investigations were conducted according to Declaration of Helsinki principles.

\section{RESULTS}

Association to R702W, G909R, and leu 1007 fsins C

There was no significant difference in allele frequencies between controls and the cohorts of psoriatic arthritis or psoriasis vulgaris patients for any of the three variants (table 2). Overall, 82 of 376 controls $(21.8 \%)$ had at least one variant of the CARD15 gene, compared with 43 of 281 probands $(15.3 \%)$ with psoriasis vulgaris $\left(\chi^{2}=4.42\right.$, $\mathrm{p}=0.036)$, and 74 of 375 probands $(19.7 \%)$ with psoriatic arthritis (NS). Hardy-Weinberg equilibrium for the three mutations was confirmed in all cohorts.

\section{Association to R702W, G908R, and leu $1007 \mathrm{fsins} C$ after stratification for the type of joint involvement} We stratified the psoriatic arthritis patient group for oligoarthritis (85 cases), polyarthritis (258 cases), spinal involvement (72 cases), and radiological evidence of spondylitis (40 cases). No significant differences in the allele frequencies for any of the three polymorphisms between the whole psoriatic arthritis cohort and any of the stratification groups were found (data not shown).

Table 2 Allele frequencies of the three variants of the CARD15 gene in patients and controls and results of $\chi^{2}$ statistics (compared with controls)

\begin{tabular}{|c|c|c|c|c|c|c|c|c|}
\hline \multirow[b]{2}{*}{ Polymorphism } & & \multirow{2}{*}{$\frac{\text { Controls }}{\text { n (\%) }}$} & \multicolumn{3}{|c|}{ Psoriasis vulgaris } & \multicolumn{3}{|c|}{ Psoriatic arthritis } \\
\hline & & & n (\%) & $\chi^{2}$ & $p$ Value & $\mathrm{n}(\%)$ & $\chi^{2}$ & p Value \\
\hline R702W & $\begin{array}{l}\text { wt } \\
\text { mut }\end{array}$ & $\begin{array}{l}666(94) \\
46(6)\end{array}$ & $\begin{array}{l}584(95) \\
28(5)\end{array}$ & 1.255 & 0.263 & $\begin{array}{l}691(94) \\
43(6)\end{array}$ & 0.227 & 0.634 \\
\hline G908R & $\begin{array}{l}\text { wt } \\
\text { mut }\end{array}$ & $\begin{array}{l}710(98) \\
16(2)\end{array}$ & $\begin{array}{l}542(99) \\
6(1)\end{array}$ & 2.263 & 0.132 & $\begin{array}{l}726(98) \\
14(2)\end{array}$ & 0.178 & 0.673 \\
\hline leu1007fsins C & $\begin{array}{l}\text { wt } \\
\text { mut }\end{array}$ & $\begin{array}{l}716(97) \\
24(3)\end{array}$ & $\begin{array}{l}549(98) \\
13(2)\end{array}$ & 1.001 & 0.317 & $\begin{array}{l}715(97) \\
23(3)\end{array}$ & 0.019 & 0.890 \\
\hline
\end{tabular}

mut, mutant allele probe; wt, wild type allele probe. 
Table 3 Allele frequencies of the three variants of the CARD 15 gene in patients and controls after stratification for the PSORS1 associated HCR haplotype HCR*WWCC and results of $\chi^{2}$ statistics (compared with controls)

\begin{tabular}{|c|c|c|c|c|c|c|c|c|}
\hline \multirow[b]{2}{*}{ Polymorphism } & & \multirow{2}{*}{$\frac{\text { Controls }}{\text { n (\%) }}$} & \multicolumn{3}{|c|}{ Psoriasis vulgaris } & \multicolumn{3}{|c|}{ Psoriatic arthritis } \\
\hline & & & $n(\%)$ & $\chi^{2}$ & $\mathrm{p}$ Value & $n$ (\%) & $\chi^{2}$ & p Value \\
\hline \multicolumn{9}{|c|}{ HCR*WWCC positive } \\
\hline $\mathrm{R} 702 \mathrm{~W}$ & $\begin{array}{l}\text { wt } \\
\text { mut }\end{array}$ & $\begin{array}{l}231(91) \\
23(9)\end{array}$ & $\begin{array}{l}356(96) \\
16(4)\end{array}$ & 5.839 & 0.016 & $\begin{array}{l}370(94) \\
22(6)\end{array}$ & 2.819 & 0.093 \\
\hline G908R & $\begin{array}{l}\text { wt } \\
\text { mut }\end{array}$ & $\begin{array}{l}252(98) \\
4(2)\end{array}$ & $\begin{array}{l}357(99) \\
5(1)\end{array}$ & 0.034 & 0.853 & $\begin{array}{l}385 \text { (98) } \\
7(2)\end{array}$ & 0.046 & 0.830 \\
\hline leu1007fsinsC & $\begin{array}{l}\text { wt } \\
\text { mut }\end{array}$ & $\begin{array}{l}249(97) \\
7(3)\end{array}$ & $\begin{array}{l}365(98) \\
9(2)\end{array}$ & 0.066 & 0.797 & $\begin{array}{l}383(98) \\
7(2)\end{array}$ & 0.643 & 0.422 \\
\hline \multicolumn{9}{|c|}{ HCR*WWCC negative } \\
\hline $\mathrm{R} 702 \mathrm{~W}$ & $\begin{array}{l}\text { wt } \\
\text { mut }\end{array}$ & $\begin{array}{l}431(95) \\
23(5)\end{array}$ & $\begin{array}{l}177(94) \\
11(6)\end{array}$ & 0.163 & 0.686 & $\begin{array}{l}321(94) \\
21(6)\end{array}$ & 0.431 & 0.511 \\
\hline G908R & $\begin{array}{l}\text { wt } \\
\text { mut }\end{array}$ & $\begin{array}{l}454(97) \\
12(3)\end{array}$ & $\begin{array}{l}187(99) \\
1(1)\end{array}$ & 2.87 & 0.09 & $\begin{array}{l}337(98) \\
7(2)\end{array}$ & 0.252 & 0.616 \\
\hline leu1007fsinsC & $\begin{array}{l}\text { wt } \\
\text { mut }\end{array}$ & $\begin{array}{l}464(97) \\
16(3)\end{array}$ & $\begin{array}{l}184(98) \\
4(2)\end{array}$ & 0.676 & 0.411 & $\begin{array}{l}333(96) \\
15(4)\end{array}$ & 0.534 & 0.465 \\
\hline
\end{tabular}

\section{Stratification for PSORS 1}

We found deviation from Hardy-Weinberg equilibrium for the two HCR SNPs owing to a significant excess of patients heterozygous for the risk alleles. In contrast, HardyWeinberg equilibrium was confirmed in the psoriatic arthritis and control groups.

As expected, we found strong association to the risk alleles of the two HCR SNPs, although higher in the psoriasis vulgaris group ( 1.3 E-14 for HCR-325*T and 1.3 E-8 for HCR$2327^{*} \mathrm{G}$ ) than in the psoriatic arthritis group (1.3 E-7 for HCR-325*T and 4.47 E-4 for HCR- $2327^{*} \mathrm{G}$ ). We also noted a significant difference in the number of $\mathrm{HCR}^{\star}$ WWCC carriers (187 psoriasis vulgaris subjects $(66.5 \%) \quad v 198$ psoriatic arthritis subjects $\left.(53.0 \%) ; \chi^{2}=12.00, p=5.0 \mathrm{E}-4\right)$.

\section{Association to R702W, G908R, and leu $1007 f$ sinsC after stratification for PSORS 1}

Next we stratified controls and both groups of patients for the risk haplotype $\mathrm{HCR}^{*}$ WWCC. This resulted in a weak association of the wild type allele $\mathrm{C}$ of $\mathrm{R} 702 \mathrm{~W}$ in the subgroup of psoriasis vulgaris patients positive for the risk haplotype $\left(\chi^{2}=5.839, \mathrm{p}=0.016\right)$. No association could be observed in any of the other subgroups (table 3 ).

\section{DISCUSSION}

We failed to find any association to any of the three more common variants of CARD15 with psoriatic arthritis or psoriasis vulgaris. Our results in large cohorts of patients confirm previous studies of smaller psoriasis populations that did not find association of the CARD15 alleles to the skin disease. $^{78}$ However, an earlier published association of psoriatic arthritis, specially with the R702W mutation, in a Newfoundland population" was not confirmed. This lack of association is in agreement with a recent Italian study that also failed to reproduce the Canadian results. ${ }^{12}$ Whereas both these earlier contradictory studies suffer from a somewhat limited sample size, the results of our present investigation on cohorts of twice the size are clearly much more robust to type I errors. The discordance of our results with the Canadian study might also be explained by the uniqueness of the Newfoundland population as a classical genetic founder population, which might account for different allele frequencies. Alternatively, extended linkage disequilibrium in this special ethnic background between CARD15 and the true susceptibility gene could be envisaged as a more likely alternative explanation.
The proportion of patients positive for the HCR risk haplotype, as an indirect measure of the PSORSI risk allele, in the present investigation is in the expected range known from other studies on psoriasis ${ }^{16}$ and psoriatic arthritis. ${ }^{17}$ The large overlap of patients with and without arthritis positive for the PSORS1 risk allele suggests similar genetic factors in both groups. Nevertheless, the significant difference in PSORS 1 risk allele frequency between the two patient groups might also indicate differential genetic factors contributing to the development of psoriatic arthropathy.

Overall, our data indicate that none of the three most common independent variants of the CARD15 gene is associated with psoriatic arthritis (including any subphenotype of joint involvement) or psoriasis vulgaris in the German population. Thus our study does not support a major contribution of the CARD15 polymorphisms to the pathogenesis of psoriatic joint and skin disease, at least in this population.

\section{ACKNOWLEDGEMENTS}

We are indebted to all patients who participated in this study. We thank Verena Popp and Olga Zwenger for excellent technical assistance. This work was supported in part by the Interdisciplinary Centre for Clinical Research (Project IZKF B32) of the University of Erlangen-Nuremberg with funds of the Research and Education Federal Ministry (01 KS 0002) and the German Research Foundation (Deutsche Forschungsgemeinschaft, DFG, Tr 228/5-4 and Re 679/104).

\section{Authors' affiliations}

J Lascorz, U Hüffmeier, A Reis, Institute of Human Genetics, University Erlangen-Nuremberg, Germany

H Burkhardt, B Böhm, Department of Internal Medicine III

(Rheumatology) and Institute of Clinical Immunology, University Erlangen-Nuremberg, Germany

F Schürmeyer-Horst, $\mathrm{H}$ Traupe, Department of Dermatology, University of Münster, Germany

J Lohmann, M Ständer, Psoriasis Rehabilitation Hospital, Bad Bentheim, Germany

J Wendler, Rheumatologische Schwerpunktpraxis, Erlangen, Germany R Kelsch, C Baumann, Institute for Transfusion Medicine, University Clinics of Münster, Germany

W Küster, TOMESA Clinics, Bad Salzschlirf, Germany

Correspondence to: Professor Dr André Reis, Institute of Human Genetics, University of Erlangen-Nuremberg, Schwabachanlage 10, 91054 Erlangen, Germany; reis@humgenet.uni-erlangen.de 


\section{REFERENCES}

1 Hugot JP, Chamaillard M, Zouali H, Lesage S, Cezard JP, Belaiche J, et al. Association of NOD2 leucine-rich repeat variants with susceptibility to Crohn's disease. Nature 2001:411:599-603.

2 Ogura Y, Bonen DK, Inohara N, Nicolae DL, Chen FF, Ramos R, et al. A frameshift mutation in NOD2 associated with susceptibility to Crohn's disease. Nature 2001;411:603-6.

3 Lee Fi, Bellary SV, Francis C. Increased occurrence of psoriasis in patients with Crohn's disease and their relatives. Am J Gastroenterol 1990;85:962-3.

4 Scarpa R, Manguso F, D'Arienzo A, D'Armiento FP, Astarita C, Mazzacca G, et al. Microscopic inflammatory changes in colon of patients with both active psoriasis and psoriatic arthritis without bowel symptoms. J Rheumatol 2000;27:1241-6

5 Nair RP, Henseler T, Jenisch S, Stuart P, Bichakjian CK, Lenk W, et al. Evidence for two psoriasis susceptibility loci (HLA and $17 q$ ) and two novel candidate regions (16q and 20p) by genome-wide scan. Hum Mol Genet 1997;6:1349-56

6 Karason A, Gudjonsson JE, Upmanyu R, Antonsdottir AA, Hauksson VB, Runasdottir $\mathrm{EH}$, et al. A susceptibility gene for psoriatic arthritis maps to chromosome 16q: evidence for imprinting. Am J Hum Genet 2003;72:125-31.

7 Nair RP, Stuart P, Ogura Y, Inohara N, Chia NV, Young L, et al. Lack of association between NOD2 3020insC frameshift mutation and psoriasis. $J$ Invest Dermatol 2001;117:1671-2.
8 Borgiani P, Vallo L, D'Apice MR, Giardina E, Pucci S, Capon F, et al. Exclusion of CARD 15/NOD2 as a candidate susceptibility gene to psoriasis in the Italian population. Eur J Dermatol 2002;12:540-2.

9 Rahman P, Bartlett S, Siannis F, Pellett FJ, Farewell VT, Peddle L, et al. CARD 15: a pleiotropic autoimmune gene that confers susceptibility to psoriatic arthritis. Am J Hum Genet 2003;73:677-81.

10 Miceli-Richard C, Zouali H, Lesage S, Thomas G, Hugot JP, Said-Nahal R, et al. CARD15/NOD2 analyses in spondylarthropathy. Arthritis Rheum 2002;46: 1405-6.

11 Steer S, Fisher SA, Fife M, Cuthbert A, Newton J, Wordsworth P, et al. Development of rheumatoid arthritis is not associated with two polymorphisms in the Crohn's disease gene CARD15. Rheumatology 2003;42:304-7.

12 Giardina E, Novelli G, Costanzo A, Nistico S, Bulli C, Sinibaldi C, et al. Psoriatic arthritis and CARD15 gene polymorphisms: no evidence for association in the Italian population. J Invest Dermatol 2004; 122:1 106-7.

13 Asumalahti K, Veal C, Laitinen T, Suomela S, Allen M, Elomaa O, et al. Coding haplotype analysis supports HCR as the putative susceptibility gene for psoriasis at the MHC PSORS1 locus. Hum Mol Genet 2002;1 1:589-97.

14 Moll JM, Wright V. Psoriatic arthritis. Semin Arthritis Rheum 1973;3:55-78.

15 Stephens M, Smith NJ, Donnelly P. A new statistical method for haplotype reconstruction from population data. Am J Hum Genet 2001 ;68:978-89.

16 Queiro R, Torre JC, Gonzalez S, Lopez-Larrea C, Tinture T, Lopez-Lagunas I. HLA antigens may influence the age of onset of psoriasis and psoriatic arthritis. J Rheumatol 2003;30:505-7.

17 Gladman DD, Anhorn KA, Schachter RK, Mervart H. HLA antigens in psoriatic arthritis. J Rheumatol 1986;13:586-9. 